\title{
Steroid Minimization in Pediatric Renal Transplantation
}

Keith K. Lau ${ }^{1}$ and Lavjay Butani'**

${ }^{1}$ Department of Pediatric Nephrology, McMaster University, Hamilton, Ontario, Canada

${ }^{2}$ Department of Pediatric Nephrology, University of California Davis, Sacramento, CA, USA

\section{Introduction}

Corticosteroids have been the mainstay of successful immunosuppressive strategies since the early days of renal transplantation [1-3]. However, success has not come without a price; long-term use of steroids is associated with well-known metabolic and bone-related adverse effects that lead to significant long-term morbidity [4]. In addition to effects on the cardiovascular and musculoskeletal organ systems, pediatric nephrologists have also had to address concerns related to the deleterious effects of steroids on growth and possible impact on non-adherence due to their cosmetic side effects.

The availability of potent induction agents and newer maintenance therapies has prompted and facilitated the development of novel regimens without the use of maintenance steroids to avoid the aforementioned side effects. The feasibility of complete avoidance of steroids in adults after renal transplantation was first suggested by an open label Canadian multicenter trial [5]. Since then, reports from other centers have also confirmed the efficacy and safety of various steroid minimization or avoidance regimens in adults [6-9]. These studies have also provided evidence that renal allograft recipients managed with less steroid exposure experience benefits such as a lower incidence of hypertension, diabetes, weight gain and hyperlipidemia.

Several multicenter randomized control trials, that directly compare the risks and benefits of rapid withdrawal or complete avoidance of steroids with regimens using maintenance steroids, in adult patients after renal transplantation have been published [10-15]. Most of these trials have demonstrated no increase in the incidence of acute rejection when steroids are minimized after transplantation [14]. Data on metabolic and cardiovascular benefits of steroid minimization are less robust although the studies do show a lower need for antihyperglycemic and lipid-lowering agents, lesser weight gain and better triglyceride levels with steroid avoidance $[13,15]$.

\section{Advantages Seen in Children}

As pediatric nephrologists, what can we learn from the adult data? In addition to all the adverse effects seen in adults, children after renal transplantation are prone to growth impairment and susceptible to non-adherence attributed in part to body disfigurement from chronic use of steroids. Children come to transplant with a mean height $\mathrm{z}$ score of -1.75 to begin with and this can further be compounded by steroid exposure after transplantation. Since children are not small adults and their immune systems are different, despite the success of steroid minimization in adults, pediatric nephrologists have been slow to follow although the tide is slowly turning [16]. According to the 2010 Annual report of the North American Pediatric Renal Trials and Collaborative Studies, more children are being managed without corticosteroids after transplantation in recent years; the 30 day posttransplant use of steroids decreased from $95 \%$ in 2002 to $49 \%$ in 2009. It is therefore prime time to re-evaluate the role of steroid minimization in children undergoing renal transplantation.

Since the first anecdotal success by Birkeland et al with the use of a steroid free regimen in 14 pediatric patients, many centers, including ours, have reported their successful experience with steroid minimization in pediatric allograft recipients, using various novel protocols in a non-randomized manner [17-24]. These reports not only further support the feasibility and safety of steroid avoidance or minimization but they also affirm the potential metabolic benefits observed in adult patients. However, an improvement in linear growth was not universally observed among children receiving fewer steroids. We now have a few prospective randomized trials of steroid minimization/avoidance in children that are shedding light on this area [25-27]. The first multicenter randomized trial included 42 children from eight German centers and was designed to compare late (3 month) steroid withdrawal with a steroid based protocol [25]. All children (n = 42) received triple therapy (cyclosporine/mycophenolate mofetil/ steroids) at transplantation. Twenty three children were randomized to undergo steroid minimization. In addition to a comparable rate of acute rejection at 12 months between the 2 groups, the children in the steroid minimization group displayed significantly: increased linear growth, less weight gain, lower incidence of hypertension and better lipid profile. These benefits persisted at the 2 year follow-up [26]. The impact of early steroid withdrawal in children was addressed by another multicenter randomized trial (TWIST Study), although data are only available for a 6 month of follow-up [27]. The steroid withdrawal group $(n=98)$ received 2 doses of daclizumab and tapering doses of steroids such that children were off steroids by post-operative day 5 . The control group $(n=98)$ received no induction therapy but received maintenance steroids. Both groups were maintained on tacrolimus and mycophenolate mofetil. At a 6 month follow-up, biopsy proven acute rejection was comparable in both groups $(10.7 \%$ in the withdrawal group and $7.1 \%$ in the control group). Metabolic benefits included an improved lipid profile and lower incidence of new onset diabetes in the steroid withdrawal arm. The steroid withdrawal group also had improved linear growth after transplantation. Hence, data from the available pediatric studies, albeit limited, corroborate adult findings with additional benefits of better linear growth.

Recent concerns, however, have arisen, based on studies from our center, regarding the long term risks of steroid-minimization. Although based on a very small sample size, there is the possibility that without the safety-net afforded by steroids, humoral rejection may occur more frequently, especially in patients who are non-adherent to their medication regimen [28]. Since humoral rejection can have very significant long term implications on graft survival, this is an area that

*Corresponding author: Lavjay Butani, Department of Pediatric Nephrology, University of California Davis, 2516 Stockton Blvd, Sacramento, CA 95817, USA, Tel: 916-734-8118; Fax: 916-734-0629; E-mail: Lavjay.butani@ucdmc.ucdavis.edu

Received February 17, 2012; Accepted February 19, 2012; Published February 21, 2012

Citation: Lau KK, Butani L (2012) Steroid Minimization in Pediatric Renal Transplantation. J Nephrol Therapeutic 2:e105. doi:10.4172/2161-0959.1000e105

Copyright: ( 2012 Lau KK, et al. This is an open-access article distributed under the terms of the Creative Commons Attribution License, which permits unrestricted use, distribution, and reproduction in any medium, provided the original author and source are credited. 
needs to be studied more meticulously. Another potential concern is the long term impact of the low HDL levels that are seen in patients who are not receiving corticosteroids, on cardiovascular health [29].

Notwithstanding these concerns, potential benefits of avoiding steroids, in our opinion, seem to outweigh the risks. However, more rigorous study on the appearance and trajectory of de novo donor specific antibodies after transplantation and long term cardiovascular outcomes in children and in adults are needed. Until then, steroid minimization should certainly be considered and offered as a viable strategy to children and their families, but utilized cautiously and with close monitoring.

\section{References}

1. Goodwin WE, Kaufman JJ, Mims MM, Turner RD, Glassock R, et al. (1963) Human renal transplantation. I. Clinical experiences with six cases of renal homotransplantation. J Urol 89: 13-24

2. Starzl TE, Marchioro TL, Waddell WR (1963) The Reversal of Rejection in Human Renal Homografts with Subsequent Development of Homograft Tolerance. Surg Gynecol Obstet 117: 385-395.

3. Murray JE, Merrill JP, Harrison JH, Wilson RE, Dammin GJ (1963) Prolonged survival of human-kidney homografts by immunosuppressive drug therapy. $\mathrm{N}$ Engl J Med 268: 1315-1323.

4. Lerut JP (2003) Avoiding steroids in solid organ transplantation. Transpl Int 16: $213-224$

5. Cole E, Landsberg D, Russell D, Zaltzman J, Kiberd B, et al. (2001) A pilot study of steroid-free immunosuppression in the prevention of acute rejection in renal allograft recipients. Transplantation 72: 845-850.

6. Kasiske BL, Zeier MG, Chapman JR, Craig JC, Ekberg H, et al. (2010) KDIGO clinical practice guideline for the care of kidney transplant recipients: a summary. Kidney Int 77: 299-311.

7. Matas AJ, Kandaswamy R, Gillingham KJ, McHugh L, Ibrahim H, et al. (2005) Prednisone-free maintenance immunosuppression-a 5-year experience. Am J Transplant 5: 2473-2478.

8. Rostaing L, Cantarovich D, Mourad G, Budde K, Rigotti P, et al. (2005) Corticosteroid-free immunosuppression with tacrolimus, mycophenolate mofetil, and daclizumab induction in renal transplantation. Transplantation 79: $807-814$

9. ter Meulen CG, van Riemsdijk I, Hene RJ, Christiaans MH, Borm GF, et al. (2004) Steroid-withdrawal at 3 days after renal transplantation with anti-IL-2 receptor alpha therapy: a prospective, randomized, multicenter study. Am J Transplant 4: 803-810.

10. Vincenti F, Schena FP, Paraskevas S, Hauser IA, Walker RG, et al. (2008) A randomized, multicenter study of steroid avoidance, early steroid withdrawal or standard steroid therapy in kidney transplant recipients. Am J Transplant 8: 307-316.

11. Vincenti F, Monaco A, Grinyo J, Kinkhabwala M, Roza A (2003) Multicente randomized prospective trial of steroid withdrawal in renal transplant recipients receiving basiliximab, cyclosporine microemulsion and mycophenolate mofetil. Am J Transplant 3: 306-311.

12. Kumar MS, Xiao SG, Fyfe B, Sierka D, Heifets M, et al. (2005) Steroid avoidance in renal transplantation using basiliximab induction, cyclosporinebased immunosuppression and protocol biopsies. Clin transplant 19: 61-69.

13. Woodle ES, Peddi VR, Tomlanovich S, Mulgaonkar S, Kuo PC (2010) A prospective, randomized, multicenter study evaluating early corticosteroid withdrawal with Thymoglobulin in living-donor kidney transplantation. Clin Transplant 24: 73-83.

14. Cantarovich D, Rostaing L, Kamar N, Saint-Hillier Y, Ducloux D, et al. (2010) Corticosteroid avoidance in adult kidney transplant recipients under rabbit anti-T-lymphocyte globulin, mycophenolate mofetil and delayed cyclosporine microemulsion introduction. Transpl Int 23: 313-324.

15. Nematalla $\mathrm{AH}$, Bakr MA, Gheith OA, Elagroudy AE, Elshahawy el-M, et al (2007) Steroid-avoidance immunosuppression regimen in live-donor renal allotransplant recipients: a prospective, randomized, controlled study. Exp Clin Transplant 5: 673-679.

16. Ettenger RB (1992) Age and the immune response in pediatric renal transplantation. Eur J pediatr 1:S7-8.

17. Delucchi A, Valenzuela M, Ferrario M, Lillo AM, Guerrero JL, et al. (2007) Early steroid withdrawal in pediatric renal transplant on newer immunosuppressive drugs. Pediatr Transplant 11: 743-748.

18. Lau KK, Haddad MN, Berg GM, Perez RV, Butani L (2007) Rapid steroid discontinuation for pediatric renal transplantation: a single center experience. Pediatr Transplant 11: 504-510.

19. Lau KK, Berg GM, Schjoneman YG, Perez RV, Butani L (2010) Extended experience with a steroid minimization immunosuppression protocol in pediatric renal transplant recipients. Pediatr Transplant 14: 488-495.

20. Sarwal MM, Vidhun JR, Alexander SR, Satterwhite T, Millan M, et al. (2003) Continued superior outcomes with modification and lengthened follow-up of a steroid-avoidance pilot with extended daclizumab induction in pediatric renal transplantation. Transplantation 76: 1331-1339.

21. Oberholzer J, John E, Lumpaopong A, Testa G, Sankary HN, et al. (2005) Early discontinuation of steroids is safe and effective in pediatric kidney transplant recipients. Pediatr Transplant 9: 456-463.

22. Bhakta N, Marik J, Malekzadeh M, Gjertson D,Ettenger R (2008) Can pediatric steroid-free renal transplantation improve growth and metabolic complications? Pediatr Transplant 12: 854-861.

23. Hamiwka LA, Burns A, Bell L (2006) Prednisone withdrawal in pediatric kidney transplant recipients on tacrolimus-based immunosuppression: four-year data Pediatr Transplant 10: 337-344.

24. Motoyama O, Hasegawa A, Ohara T, Satoh M, Shishido S, et al. (2005) A prospective trial of steroid withdrawal after renal transplantation treated with cyclosporine and mizoribine in children: results obtained between 1990 and 2003. Pediatr Transplant 9: 232-238.

25. Hocker B, Weber LT, Feneberg R, Drube J, John U, et al. (2009) Prospective randomized trial on late steroid withdrawal in pediatric renal transplant recipients under cyclosporine microemulsion and mycophenolate mofetil. Transplantation 87: 934-941.

26. Hocker B, Weber LT, Feneberg R, Drube J, John U, et al. (2010) Improved growth and cardiovascular risk after late steroid withdrawal: 2-year results of a prospective, randomised trial in paediatric renal transplantation. Nephrol Dia Transplant 25: 617-624.

27. Grenda R, Watson A, Trompeter R, Tonshoff B, Jaray J, et al. A randomized trial to assess the impact of early steroid withdrawal on growth in pediatric renal transplantation: the TWIST study. Am J Transplant 10: 828-836.

28. Butani L, Gallay BJ (2011) Acute humoral rejection in pediatric renal transplant recipients receiving steroid minimization immunosuppression. Pediatr Transplant.

29. Lau KK, Tancredi DJ, Perez RV, Butani L (2010) Unusual pattern of dyslipidemia in children receiving steroid minimization immunosuppression after renal transplantation. Clin J Am Soc Nephrol 5: 1506-1512. 